\title{
Perivascular spaces are associated with tau pathophysiology and synaptic dysfunction in early Alzheimer's continuum
}

\author{
Natalia Vilor-Tejedor 1,2,3,4* , lacopo Ciampa ${ }^{5}$, Grégory Operto ${ }^{1,6,7}$, Carles Falcón ${ }^{1,6,8}$, Marc Suárez-Calvet ${ }^{1,6,7,9}$, \\ Marta Crous-Bou 1,10,11, Mahnaz Shekari 1,4,6, Eider M. Arenaza-Urquijo 1,6,7, Marta Milà-Alomà 1,4,6,7, \\ Oriol Grau-Rivera ${ }^{1,6,7,9}$, Carolina Minguillon 1,6,7, Gwendlyn Kollmorgen ${ }^{12}$, Henrik Zetterberg 13,14,15,16, \\ Kaj Blennow ${ }^{13,14}$, Roderic Guigo 2,4 , José Luis Molinuevo ${ }^{1,4,6,7^{*}}$ (D) and Juan Domingo Gispert ${ }^{1,4,6,8^{*}}$ (Dfor the ALFA \\ study
}

\begin{abstract}
Background: Perivascular spaces (PVS) have an important role in the elimination of metabolic waste from the brain. It has been hypothesized that the enlargement of PVS (ePVS) could be affected by pathophysiological mechanisms involved in Alzheimer's disease (AD), such as abnormal levels of CSF biomarkers. However, the relationship between ePVS and these pathophysiological mechanisms remains unknown.
\end{abstract}

Objective: We aimed to investigate the association between ePVS and CSF biomarkers of several pathophysiological mechanisms for AD. We hypothesized that ePVS will be associated to CSF biomarkers early in the AD continuum (i.e., amyloid positive cognitively unimpaired individuals). Besides, we explored associations between ePVS and demographic and cardiovascular risk factors.

Methods: The study included 322 middle-aged cognitively unimpaired participants from the ALFA + study, many within the Alzheimer's continuum. NeuroToolKit and Elecsys ${ }^{\circledR}$ immunoassays were used to measure CSF A $442, A \beta 40$, p-tau and t-tau, NfL, neurogranin, TREM2, YKL40, GFAP, IL6, S100, and a-synuclein. PVS in the basal ganglia (BG) and centrum semiovale (CS) were assessed based on a validated 4-point visual rating scale. Odds ratios were calculated for associations of cardiovascular and AD risk factors with ePVS using logistic and multinomial models adjusted for relevant confounders. Models were stratified by A $\beta$ status (positivity defined as A $\beta 42 / 40<0.071$ ).

Results: The degree of PVS significantly increased with age in both, BG and CS regions independently of cardiovascular risk factors. Higher levels of $p$-tau, t-tau, and neurogranin were significantly associated with ePVS in the CS of A positive individuals, after accounting for relevant confounders. No associations were detected in the BG neither in $A \beta$ negative participants.

Conclusions: Our results support that ePVS in the CS are specifically associated with tau pathophysiology, neurodegeneration, and synaptic dysfunction in asymptomatic stages of the Alzheimer's continuum.

\footnotetext{
*Correspondence: nvilor@barcelonabeta.org; jlmolinuevo@barcelonabeta.

org; jdgispert@barcelonabeta.org

1 Barcelonaßeta Brain Research Center (BBRC), Pasqual Maragall

Foundation, Barcelona, Spain

Full list of author information is available at the end of the article
}

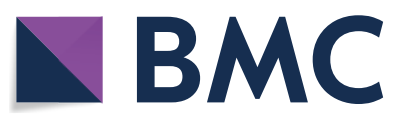

(c) The Author(s) 2021. Open Access This article is licensed under a Creative Commons Attribution 4.0 International License, which permits use, sharing, adaptation, distribution and reproduction in any medium or format, as long as you give appropriate credit to the original author(s) and the source, provide a link to the Creative Commons licence, and indicate if changes were made. The images or other third party material in this article are included in the article's Creative Commons licence, unless indicated otherwise in a credit line to the material. If material is not included in the article's Creative Commons licence and your intended use is not permitted by statutory regulation or exceeds the permitted use, you will need to obtain permission directly from the copyright holder. To view a copy of this licence, visit http://creativecommons.org/licenses/by/4.0/. The Creative Commons Public Domain Dedication waiver (http://creativeco mmons.org/publicdomain/zero/1.0/) applies to the data made available in this article, unless otherwise stated in a credit line to the data. 
Keywords: Alzheimer's disease, MRI, CSF biomarkers, Perivascular spaces, Tau pathophysiology, Virchow-Robin spaces

\section{Background}

Perivascular spaces (PVS) [1, 2], also known as VirchowRobin spaces, facilitate CSF transport from the basal cisterns into the brain interstitial fluid (ISF) [3] and have an important role in the elimination of metabolic waste and fluid from the brain [4]. Interestingly, water influx into the CSF flow through PVS could play a role equivalent to the one in the lymphatic system and it recently gained substantial attention due to its relation to amyloid- $\beta$ (A $\beta)$ clearance [5-7]. Indeed, enlargement of PVS (ePVS) may result in impaired ISF drainage and has been shown to be associated with cerebral amyloid angiopathy in cognitively impaired patients $[8,9]$, and with peripheral neuroinflammatory biomarkers in the elderly $[10,11]$. The impairment of this biological mechanism might contribute to the development of $\mathrm{AD}$ pathophysiology, characterized by $A \beta$ plaques and tau tangles. On top of these, several other pathophysiological mechanisms have been shown to be altered in preclinical AD stages [12].

The main hypothesis of our study was to investigate whether altered levels of CSF AD biomarkers were associated with ePVS in a sample of middle-aged cognitively unimpaired participants, many within the Alzheimer's continuum. The term "Alzheimer's continuum" is applied as an umbrella term that includes both "Alzheimer's pathological change" and "Alzheimer's disease" as defined in the NIA-AA Research Framework nomenclature [13]. The term "Alzheimer's pathologic change" is used when there is evidence of $A \beta$ pathology but not tau, whereas the term "Alzheimer's disease" is applied whenever there is evidence of both $A \beta$ and tau pathology, regardless of the clinical manifestations.

We first explored the association between PVS with demographic and cardiovascular-related risk factors and assessed the dependency of the results with $A \beta$ status. Moreover, we sought for associations between PVS with additional CSF biomarkers of several pathophysiological mechanisms involved in AD and other neurodegenerative disorders such as axonal damage (NfL), synaptic dysfunction (neurogranin), microglial (sTREM2), astroglial-related response (GFAP, YKL40, S100), other neuroinflammatory biomarkers (IL6), and $\alpha$-synuclein.

\section{Material and methods \\ Participants}

The study included participants from the ALFA study (Alzheimer and Families) at the Barcelonaßeta Brain Research Center [14], which aims at studying the preclinical stage of AD. The ALFA study (Clinicaltrials.gov
Identifier: NCT01835717) includes 2743 cognitively unimpaired participants, including a high proportion of AD patients' offspring, aged between 45 and 75 years. In this study, a subset of 322 participants from a nested study (ALFA +; NCT02485730) was included. ALFA + individuals were invited based on their specific $\mathrm{AD}$ risk profile. This $\mathrm{AD}$ profile was determined by an algorithm in which participants' AD parental history, age, number of $A P O E-\varepsilon 4$, alleles, verbal episodic memory score, and CAIDE (Cardiovascular Risk Factors, Aging, and Incidence of Dementia) score were taken into consideration. These individuals are cognitively unimpaired and, therefore, are in the preclinical stage of the Alzheimer's continuum. In terms of main demographic characteristics, the percentages do not differ from the ALFA parent cohort. In addition, all individuals included in this study have available information on APOLIPOPROTEIN $E(A P O E)$ genotype, MRI examination, CSF biomarker levels, as well as cardiovascular risk factors (Fig. 1). Notice that the average time range between MRI acquisition and CSF sampling was 44 days ( \pm 57 days). MRI acquisition and cognitive assessment were performed at the same visit.

\section{Image acquisition}

Scans were obtained with a $3 \mathrm{~T}$ scanner (Ingenia CX, Philips, Amsterdam, Netherlands). The MRI protocol was identical for all participants and included high-resolution 3D T2-weighted image: Turbo Spin Echo (TSE), voxel size $1 \times 1 \times 1 \mathrm{~mm}^{3}$, repetition time/echo time (TR/ TE): $2500 / 264 \mathrm{~ms}$, flip angle $=90^{\circ}$. In addition, a 3D T1-weighted Turbo Field Echo (TFE) sequence was acquired (voxel size $0.75 \times 0.75 \times 0.75 \mathrm{~mm}$, TR/TE: 9.90/4.6 ms, flip angle $=8^{\circ}$ ) as well as a 3D T2-FLAIR sequence (TSE, voxel size $1 \times 1 \times 1 \mathrm{~mm}$, TR/TE/TI: $5000 / 312 / 1700 \mathrm{~ms})$. Scans were visually assessed for quality and incidental findings by a trained neuroradiologist. T1w images were segmented to compute total gray matter volume and total intracranial volume (TIV) using Freesurfer 6.0 (https://surfer.nmr.mgh.harvard.edu/). In addition, white matter hyperintensities (WMH) were segmented from FLAIR images using the Lesion Segmentation Toolbox (LST; https://www.applied-statistics.de/ lst.html) for SPM12 [15].

\section{Rating of perivascular spaces}

PVS were evaluated by a radiologist using the visual rating scale developed by [16] based on T2-weighted images. The radiologist was blind to clinical assessment 


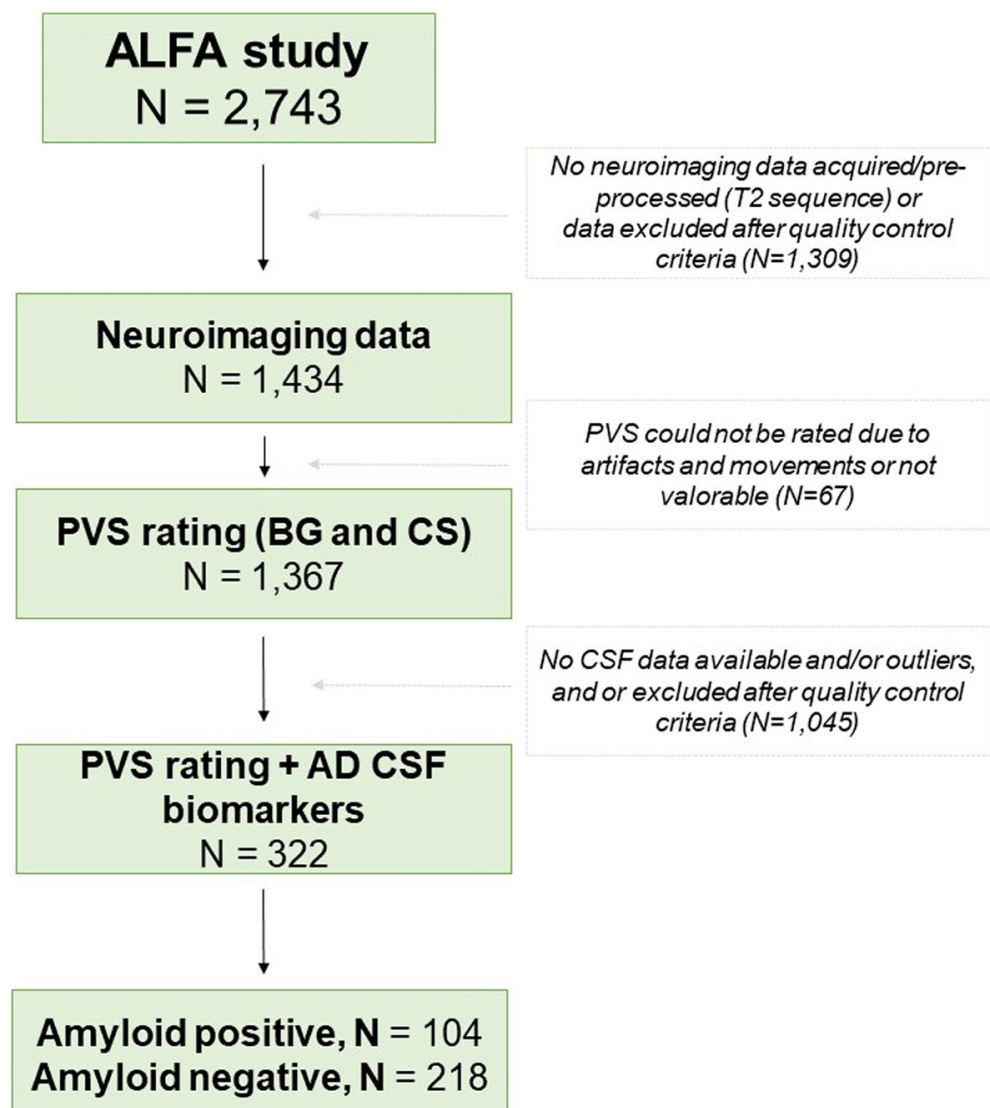

Fig. 1 Flow chart that shows the selection of the participants of the study. ALFA study, ALzheimer and FAmilies; PVS, perivascular spaces; CSF, cerebrospinal fluid; BG, basal ganglia; CS, centrum semiovale; N, sample

and quantification of variables of interest used in the study. Briefly, PVSs were quantified independently in two brain regions, including BG, and centrum semiovale (CS). PVS in BG and CS were assessed in the slice and hemisphere with the highest number and rated as 0 (no PVS; degree 0), 1 (mild; 1-10 PVS; degree 1), 2 (moderate; 11-20 PVS; degree 2), 3 (frequent; 21-40 PVS; degree 3), or 4 (severe; 40 PVS; degree 4). Examples of the PVS rating are given in Fig. 2. Participants were dichotomized according to the severity of the ePVS rating of the BG and CS (degrees 0-2 were categorized as non-severe or 0 , degrees $3-4$ were categorized as severe or 1 ).

The intra-rater agreement rate (Cohen's Kappa) of PVS rating was evaluated by estimating the intraclass correlation of two independent ratings from the same radiologist on a random sample of $20 \%$ of the subjects in the dataset. The intra-rater agreement analysis showed substantial reliability $(\kappa=0.77, p=6.02 \mathrm{e}-08$ for BG subscale; and $\kappa=0.76, p=8.2 \mathrm{e}-10$ for CS subscale).

\section{CSF collection and measurement}

The collection of CSF and measurement of biomarkers in ALFA + was previously described comprehensively [12]. In brief, CSF t-tau and p-tau were measured using the electrochemiluminescence immunoassays Elecsys ${ }^{\circledR}$ Total-tau CSF and phosphor-tau(181P) CSF on a fully automated cobas e601 instrument (Roche Diagnostics International Ltd.). The rest of the CSF biomarkers were measured with robust prototype assay as part of the NeuroToolKit (Roche Diagnostics International Ltd, Rotkreuz, Switzerland) on both cobas e 601 and e 411 instruments. All measurements were performed at the Clinical Neurochemistry Laboratory, Sahlgrenska University Hospital, Mölndal, Sweden.

$\mathrm{A} \beta$ pathology positivity $(\mathrm{A} \beta+)$ was defined by CSF $A \beta 42 / 40$ ratio. We derived the cutoffs for each of these biomarkers using a two-Gaussian mixture modeling. The cut-off was defined as the mean plus 2 standard deviations (SD) of the non-pathologic Gaussian distribution (i.e., the Gaussian with the higher mean value for $\mathrm{A} \beta 42 / 40$ ratio and the resulting cutoff was 0.071 . This 

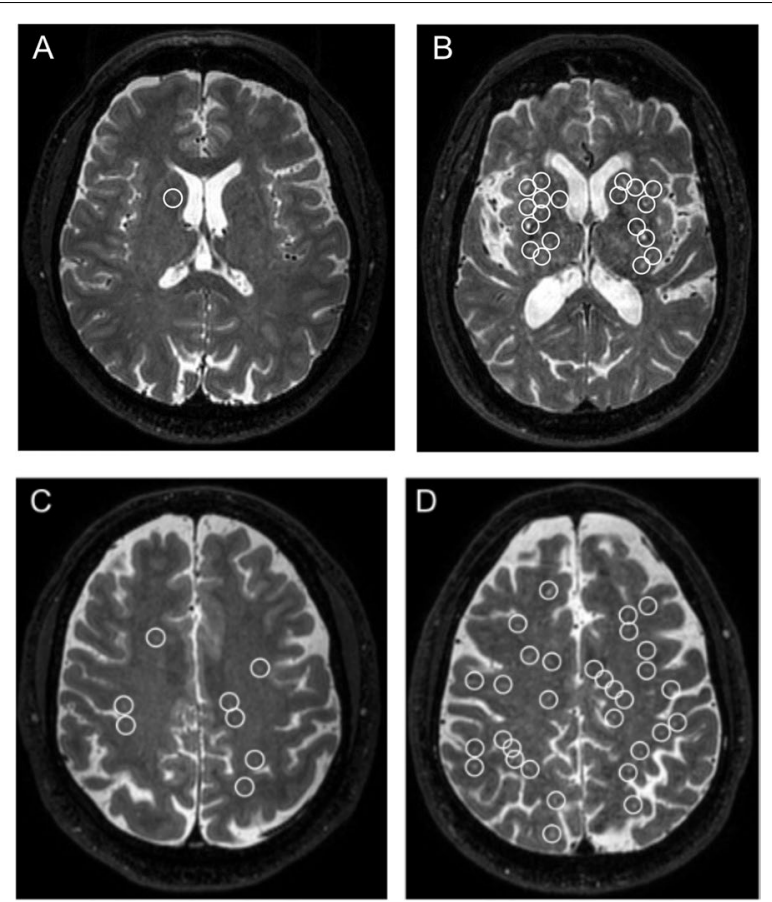

Fig. 2 Perivascular spaces rating. A Score of 1 in basal ganglia (non-severe). B Score of 4 in basal ganglia (severe). C Score of 1 (non-severe) in centrum semiovale. D Score of 4 (severe) in centrum semiovale. Circle: an enlarged Perivascular Space

approach for the definition of $A \beta+$ has been shown to be optimal for the detection of pathophysiological changes in early stages of the Alzheimer's continuum [17]. A total of 122 individuals in the study were categorized as $A \beta+$.

\section{Risk factors assessment}

Sociodemographic and clinical data were collected during face-to-face interviews by trained neuropsychologists, study nurses, and clinical neurologists. Participants' systolic and diastolic blood pressure were measured twice and the second measure was used. Total cholesterol level was obtained from a blood test (lipoprotein panel). Body mass index (BMI) was derived from the height and weight measured at the time of the interview. Physical activity was measured using the Spanish short version of the Minnesota Leisure Time Physical Activity Questionnaire [18] and participants were split into two categories: "active" (more than 150 min of moderate exercise or $75 \mathrm{~min}$ of vigorous exercise per week as recommended by the American Heart Association) or 'inactive'. Participants with systolic blood pressure levels above $140 \mathrm{mmHg}$, self-reported hypertension diagnosis, or current use of anti-hypertensive medication were considered hypertensive. Diabetes and dyslipidemia status were defined from participant self-reported diagnosis.
Moreover, based on these cardiovascular factors, we calculated a dementia risk score CAIDE (Cardiovascular Risk Factors, Aging, and Incidence of Dementia) to be included in the analysis. Further details of the calculation of CAIDE can be found in [19]. The APOE allelic variants $\varepsilon 2$, $\varepsilon 3$, and $\varepsilon 4$ were determined from allelic combinations of the rs429358 and rs7412 polymorphisms, where the $\varepsilon 4$ allele is the combination of the $\mathrm{C}$ allele at both sites [20]. Individuals were classified according to the number of $\varepsilon 4$ alleles (non-carriers, heterozygotes, homozygotes). Allele frequencies and departures from Hardy-Weinberg equilibrium were inspected.

\section{Statistical analysis}

Differences between the degree of PVS in demographic and cardiovascular variables were assessed using $X^{2}$ tests (categorical variables), one-way ANOVA (normal continuous variables), and/or non-parametric Kruskal-Wallis tests (non-normal continuous variables).

There were differences in demographics and cardiovascular factors between the degrees of PVS. Therefore, odd ratios were calculated for associations of potential risk factors with ePVS. Associations between CSF biomarkers and ePVS (higher degree of PVS) were examined in logistic regressions (BG-ePVS) and multinomial regressions (CS-ePVS) adjusting for the previous potential confounders selected through stepwise regression (backward method) to generate minimally adjusted models. All regression models were adjusted by age, sex, $A P O E-\varepsilon 4$ status, physical inactivity, total GM volume, and TIV. BG-ePVS models were additionally adjusted by systolic blood pressure, and CS-ePVS models were additionally adjusted by diastolic blood pressure.

Analyses with CSF biomarkers were stratified by $A \beta$ status, as defined by CSF A $\beta 42 / 40$ ratio, to assess whether the relationship between ePVS and CSF biomarker levels differed between individuals with normal (negative) and pathologic (positive) A $\beta$ levels. We first examined associations between ePVS and a non-pathological biomarker (A 340$)$ to assess whether ePVS might be associated with overall protein clearance by CSF. We then sought associations between ePVS and the rest of CSF biomarkers with and without correction for $A \beta 40$. This has been the final model selected in the study. All these models were corrected by relevant demographic and cardiovascular factors previously identified.

Notice that, categories of ePVS with less than 20 observations were included in the former category [individuals with degree 3 in BG-ePVS $(N=19)$, and degree 4 in CSePVS $(N=10)$. As a post hoc analysis, we excluded these categories, and we reproduced regression models and compared them with previous analyses to evaluate the 
risk of overfitting (these models produced similar results and were not presented).

Statistical significance was set at $P \leq 0.05$ and corrected using pair-wise correction (group comparisons) and false discovery rate (FDR) (association models). All statistical analyses and data visualizations were carried out using $R$ version 3.6.1.

\section{Results}

\section{Descriptive}

The mean age of the study's participants was $60.4( \pm 4.9)$ years old, and $64.5 \%$ were female. Degree 2 of ePVS was the most frequent in both BG and CS (between 42 and $44 \%$ of participants). In contrast, degree 3 in BG (5.7\%), and degree 4 in CS (3.01\%) were less commonly encountered among participants. In addition, we did not find participants with degree 4 in BG (Fig. 3). Further characteristics of the sample and the distribution of potential risk factors according to ePVS degree are shown in Table 1. Characteristics of the CSF biomarker sample according to ePVS degree are shown in Table 2, and characteristics of the sample stratified by $A \beta 42 / 40$ status are shown in Supplemental Table 1.

\section{Association between demographics and cardiovascular risk factors on ePVS}

Table 3 shows associations between demographic and cardiovascular risk factors with BG-ePVS and

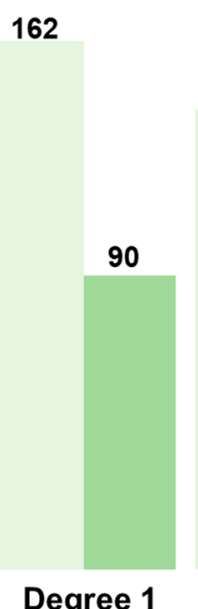

Degree

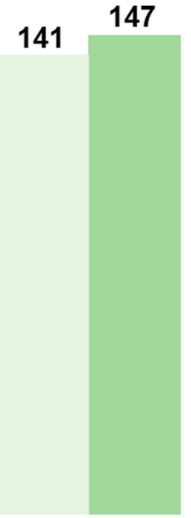

Degree 2
160

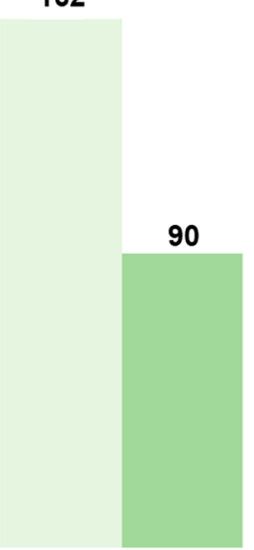

Degree 1

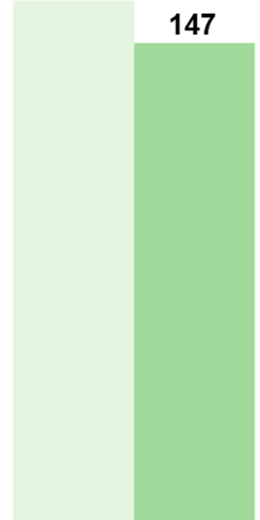

BG: Degree 2+3 CS: Degree 2
85

0

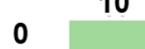

Degree 4

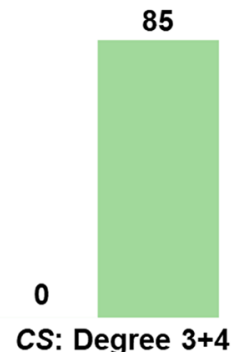

CS: Degree 3+4

Fig. 3 Distribution of Perivascular Spaces by degree of severity. Legend: BG, Basal Ganglia; CS, centrum semiovale. Model 1 shows associations correcting by age, sex and cardiovascular risk factors. Model 2 shows associations correcting by age, sex, cardiovascular risk factors and Aß40. Blue color intensities indicate the magnitude of the associations (higher levels of biomarkers). Abbreviations: AD, Alzheimer's disease; PVS, perivascular spaces; BG, basal ganglia; CS, centrum semiovale; CSF, cerebrospinal fluid; A 340 , amyloid- $\beta$ 40; $A \beta 42$, amyloid- $\beta$ 42; GFAP, glial fibrillary acidic protein; IL6, interleukin-6; NfL, neurofilament light; p-tau, phosphorylated tau; STREM2, soluble triggering receptor expressed on myeloid cells 2 (TREM2); t-tau, total tau 
Table. 1 Characteristics of the sample and group comparisons of potential risk factors across degrees of Perivascular Spaces in Basal Ganglia and Centrum Semiovale Regions. Legend: N, sample size; $n$, count of individuals for each categorical variable; SD, standard deviation; ePVS, enlarged perivascular spaces; BG, basal ganglia; CS, centrum semiovale; CAIDE, Cardiovascular Risk Factors, Aging and Incidence of Dementia; $B M I$, body mass index; WMH, white matter hyperintensities; GM, gray matter volume; TIV, total intracranial volume

\begin{tabular}{|c|c|c|c|c|c|c|c|c|c|}
\hline & \multirow[b]{2}{*}{$N$} & \multirow[b]{2}{*}{$\begin{array}{l}\text { Mean (SD) or } \\
n(\%)\end{array}$} & \multicolumn{3}{|l|}{ BG-ePVS } & \multicolumn{4}{|l|}{ CS-ePVS } \\
\hline & & & $\begin{array}{l}\text { Degree } 1 \\
(n=162)\end{array}$ & $\begin{array}{l}\text { Degree } \\
2+\text { Degree } 3 \\
(n=160)\end{array}$ & $p$ value & $\begin{array}{l}\text { Degree } 1 \\
(n=90)\end{array}$ & $\begin{array}{l}\text { Degree } 2 \\
(n=147)\end{array}$ & $\begin{array}{l}\text { Degree } 3+4 \\
(n=85)\end{array}$ & $p$ value \\
\hline Sex, $n(\%)$ & 322 & & & & 0.156 & & & & 0.549 \\
\hline Male & & $118(36.6 \%)$ & $66(40.7 \%)$ & $52(32.5 \%)$ & & 35 (38.9\%) & $56(38.1 \%)$ & $27(31.8 \%)$ & \\
\hline Female & & 204 (63.4\%) & 96 (59.3\%) & $108(67.5 \%)$ & & $55(61.1 \%)$ & $91(61.9 \%)$ & $58(68.2 \%)$ & \\
\hline Age (years) & 322 & $60.7(4.69)$ & $59.4(4.67)$ & $62.0(4.37)$ & $<0.001$ & $59.8(4.76)$ & $60.5(4.62)$ & $62.0(4.50)$ & 0.006 \\
\hline $\begin{array}{l}\text { APOE- } \varepsilon 4 \text { allele } \\
\text { status, } n(\%)\end{array}$ & 322 & & & & 0.182 & & & & 0.643 \\
\hline Non-carriers & & $156(48.4 \%)$ & $72(44.4 \%)$ & $84(52.5 \%)$ & & $43(47.8 \%)$ & $75(51.0 \%)$ & $38(44.7 \%)$ & \\
\hline Carriers & & $166(51.6 \%)$ & 90 (55.6\%) & $76(47.5 \%)$ & & 47 (52.2\%) & $72(49.0 \%)$ & 47 (55.3\%) & \\
\hline Education (years) & 318 & $13.4(3.50)$ & $13.6(3.39)$ & $13.2(3.61)$ & 0.346 & $13.3(3.22)$ & $13.8(3.50)$ & $12.9(3.76)$ & 0.188 \\
\hline Diabetes, n (\%) & 304 & & & & 0.531 & & & & 0.161 \\
\hline No & & 294 (96.7\%) & $141(95.9 \%)$ & $153(97.5 \%)$ & & 77 (93.9\%) & 137 (98.6\%) & $80(96.4 \%)$ & \\
\hline Yes & & $10(3.29 \%)$ & $6(4.08 \%)$ & $4(2.55 \%)$ & & $5(6.10 \%)$ & $2(1.44 \%)$ & $3(3.61 \%)$ & \\
\hline Dyslipidemia, n (\%) & 304 & & & & 0.406 & & & & 0.551 \\
\hline No & & $159(52.3 \%)$ & $81(55.1 \%)$ & $78(49.7 \%)$ & & $47(57.3 \%)$ & $71(51.1 \%)$ & $41(49.4 \%)$ & \\
\hline Yes & & $145(47.7 \%)$ & 66 (44.9\%) & 79 (50.3\%) & & 35 (42.7\%) & 68 (48.9\%) & $42(50.6 \%)$ & \\
\hline BMI $\left(\mathrm{kg} / \mathrm{m}^{2}\right)$ & 322 & $27.0(4.16)$ & $27.5(4.34)$ & $26.4(3.91)$ & 0.014 & $27.8(4.64)$ & $26.8(3.72)$ & $26.5(4.27)$ & 0.077 \\
\hline $\begin{array}{l}\text { Systolic Blood Pres- } \\
\text { sure }(\mathrm{mmHg})\end{array}$ & 321 & $133(15.9)$ & $131(14.9)$ & 135 (16.4) & 0.007 & $131(14.9)$ & $133(15.2)$ & $135(17.7)$ & 0.228 \\
\hline $\begin{array}{l}\text { Diastolic Blood } \\
\text { Pressure(mmHg) }\end{array}$ & 321 & $75.4(9.89)$ & $75.7(9.56)$ & $75.1(10.2)$ & 0.541 & $74.1(9.80)$ & $75.1(9.80)$ & $77.2(9.97)$ & 0.100 \\
\hline $\begin{array}{l}\text { Cholesterol (mg/ } \\
\text { dL) }\end{array}$ & 292 & $204(30.8)$ & $204(29.1)$ & $204(32.4)$ & 0.871 & $205(32.3)$ & $203(32.1)$ & $203(27.2)$ & 0.886 \\
\hline $\begin{array}{l}\text { Physical Activity, } \\
n(\%)\end{array}$ & 288 & & & & 0.089 & & & & 0.326 \\
\hline Non-active & & 55 (19.1\%) & $20(14.6 \%)$ & $35(23.2 \%)$ & & $12(15.8 \%)$ & $24(17.8 \%)$ & $19(24.7 \%)$ & \\
\hline Active & & $233(80.9 \%)$ & $117(85.4 \%)$ & $116(76.8 \%)$ & & $64(84.2 \%)$ & $111(82.2 \%)$ & $58(75.3 \%)$ & \\
\hline CAIDE score (0-15) & 286 & $6.00[4.00 ; 7.00]$ & $5.00[4.00 ; 7.00]$ & $6.00[4.00 ; 7.00]$ & 0.129 & $5.00[4.00 ; 7.00]$ & $5.00[4.00 ; 6.00]$ & $6.00[4.75 ; 7.00]$ & 0.089 \\
\hline Total GM $\left(\mathrm{mm}^{3}\right)$ & 278 & $\begin{array}{l}588,244 \\
(49,789)\end{array}$ & $\begin{array}{l}597,109 \\
(47,771)\end{array}$ & $\begin{array}{l}580,229 \\
(50,376)\end{array}$ & 0.004 & $\begin{array}{l}584,964 \\
\quad(48,140)\end{array}$ & $\begin{array}{l}590,616 \\
(50,255)\end{array}$ & $\begin{array}{l}587,617 \\
(51,210)\end{array}$ & 0.726 \\
\hline WMH (ml) & 257 & $3.33(16.6)$ & $1.43(1.72)$ & $5.08(22.9)$ & 0.068 & $1.39(1.39)$ & $4.83(23.7)$ & $2.48(2.84)$ & 0.346 \\
\hline $\operatorname{TIV}\left(\mathrm{mm}^{3}\right)$ & 278 & $\begin{array}{l}1,438,565 \\
(171,034)\end{array}$ & $\begin{array}{l}1,456,206 \\
(166,776)\end{array}$ & $\begin{array}{l}1,422,616 \\
(173,823)\end{array}$ & 0.101 & $\begin{array}{l}1,427,412 \\
(163,677)\end{array}$ & $\begin{array}{l}1,442,693 \\
(179,156)\end{array}$ & $\begin{array}{l}1,443,534 \\
(165,757)\end{array}$ & 0.792 \\
\hline
\end{tabular}

CS-ePVS. We observed that the degree of PVS significantly increased with age in both, BG and CS regions (BG, OR [CI95\%]: 1.14 [1.07, 1.23]; CS, degree 2 vs degree 1, OR [CI95\%]: $1.11[1.01,1.2]$; degree $3+4$ vs 1 , OR [CI95\%]: 1.27 [1.13,1.45]; degree $3+4$ vs 2 , OR [CI95\%]: $1.16[1.05,1.28])$.

In the CS region, specific significant predictors of increasing PVS degree were higher diastolic blood pressure, and higher WMH (degree $3+4$ vs degree 1 ,
OR[CI95\%]: 1.02[1.01, 1.03]; degree $3+4$ vs degree 1 , OR[C195\%]: 1.33[1.06, 1.67]) (Supplemental Table 2). However, they were not significant after adjusting for additional risk factors (Table 3). Interestingly, females, who did not show significant associations in individual models, presented higher risk for CS-ePVS after adjusting for cardiovascular risk factors (degree $3+4$ vs degree 1, OR [CI95\%]: 5.5 [1.59, 21.06]). Finally, we did not find a significant association between the risk of ePVS and the number of $A P O E-\varepsilon 4$ alleles. 
Table. 2 Characteristics of the sample of CSF biomarkers across degrees of perivascular spaces. Legend: $N$, sample size; $n$, count of individuals for each categorical variable; $S D$, standard deviation; $B G$, basal ganglia; $C S$, centrum semiovale; ePVS, enlarged perivascular spaces

\begin{tabular}{|c|c|c|c|c|c|c|c|c|c|}
\hline & & & BG-ePVS & & & CS-ePVS & & & \\
\hline & $N$ & Mean (SD) & $\begin{array}{l}\text { Degree } 1 \\
(n=162)\end{array}$ & $\begin{array}{l}\text { Degree } \\
2+\text { Degree } 3 \\
(n=160)\end{array}$ & $p$ value & $\begin{array}{l}\text { Degree } 1 \\
(n=90)\end{array}$ & $\begin{array}{l}\text { Degree } 2 \\
(n=147)\end{array}$ & $\begin{array}{l}\text { Degree } 3+4 \\
(n=85)\end{array}$ & $p$ value \\
\hline $\mathrm{A} \beta 42(\mathrm{pg} / \mathrm{mL})$ & 322 & $1374(604)$ & $1287(520)$ & $1462(669)$ & 0.009 & $1321(637)$ & $1392(538)$ & $1399(677)$ & 0.616 \\
\hline$A \beta 40$ & 322 & $17.9(4.94)$ & $16.8(4.32)$ & $19.0(5.28)$ & $<0.001$ & $16.5(4.43)$ & $17.9(4.55)$ & $19.3(5.71)$ & 0.001 \\
\hline $\begin{array}{l}\mathrm{A} \beta 42 / 40 \mathrm{cat}, \\
n(\%)\end{array}$ & 322 & & & & 0.102 & & & & 0.121 \\
\hline Negative & & $200(62.1 \%)$ & 93 (57.4\%) & 107 (66.9\%) & & $50(55.6 \%)$ & 100 (68.0\%) & $50(58.8 \%)$ & \\
\hline Positive & & $122(37.9 \%)$ & 69 (42.6\%) & $53(33.1 \%)$ & & $40(44.4 \%)$ & 47 (32.0\%) & $35(41.2 \%)$ & \\
\hline p-Tau (pg/mL) & 312 & $16.8(7.67)$ & $15.4(6.08)$ & $18.2(8.77)$ & 0.001 & $15.1(5.70)$ & $16.4(6.60)$ & $19.1(10.2)$ & 0.002 \\
\hline t-Tau (pg/mL) & 322 & $202(73.6)$ & $186(61.6)$ & $217(81.4)$ & $<0.001$ & $184(61.5)$ & $198(66.1)$ & $227(90.1)$ & $<0.001$ \\
\hline GFAP (pg/mL) & 322 & $7.66(2.72)$ & $7.46(3.00)$ & $7.87(2.39)$ & 0.167 & $7.22(2.13)$ & $7.43(2.55)$ & $8.54(3.32)$ & 0.002 \\
\hline YKL40 (pg/mL) & 322 & $150(55.3)$ & $136(45.7)$ & $165(60.3)$ & $<0.001$ & $139(52.6)$ & $145(46.1)$ & $171(66.7)$ & $<0.001$ \\
\hline TREM2 (pg/mL) & 322 & $8.04(2.28)$ & $7.55(2.02)$ & $8.54(2.41)$ & $<0.001$ & $7.73(2.22)$ & $7.85(2.18)$ & 8.69 (2.38) & 0.008 \\
\hline IL6 (pg/mL) & 322 & $4.08(2.04)$ & $4.20(2.16)$ & $3.97(1.90)$ & 0.311 & $4.12(1.92)$ & $4.08(2.35)$ & $4.03(1.55)$ & 0.960 \\
\hline NFL (pg/mL) & 322 & $83.4(36.7)$ & $78.8(27.7)$ & 88.1 (43.6) & 0.024 & $82.5(48.4)$ & $79.8(25.5)$ & $90.6(38.2)$ & 0.093 \\
\hline $\begin{array}{l}\text { Neurogranin } \\
(\mathrm{pg} / \mathrm{mL})\end{array}$ & 322 & $816(339)$ & 740 (299) & $893(359)$ & $<0.001$ & $716(301)$ & $809(306)$ & $933(394)$ & $<0.001$ \\
\hline $\mathrm{S} 100(\mathrm{pg} / \mathrm{mL})$ & 322 & $1.02(0.24)$ & $1.02(0.25)$ & $1.03(0.23)$ & 0.722 & $0.99(0.22)$ & $1.01(0.21)$ & $1.07(0.29)$ & 0.080 \\
\hline $\begin{array}{l}\text { a-Synuclein (pg/ } \\
\text { mL) }\end{array}$ & 322 & $245(277)$ & $212(180)$ & $278(347)$ & 0.035 & $199(147)$ & $249(265)$ & $286(381)$ & 0.108 \\
\hline
\end{tabular}

Table. 3 Associations between enlargement of perivascular spaces in basal ganglia and centrum semiovale regions, and demographic and cardiovascular risk factors. Legend: $n$, count of individuals for each categorical variable; $S D$, standard deviation; $B G$, basal ganglia; CS, centrum semiovale; ePVS, enlarged perivascular spaces; WMH, white matter hyperintensities; GM, gray matter volume; $T I V$, total intracranial volume; $O R$, odds ratio; $C$, confidence interval

\begin{tabular}{|c|c|c|c|}
\hline BG-ePVS & CS-ePVS & & \\
\hline OR $(95 \% \mathrm{Cl})$ & OR $(95 \% \mathrm{Cl})$ & OR $(95 \% \mathrm{Cl})$ & OR (95\% Cl) \\
\hline Degree $2+3$ vs Degree 1 & Degree 2 vs Degree 1 & Degree $3+4$ vs Degree 1 & Degree $3+4$ vs Degree 2 \\
\hline
\end{tabular}

\begin{tabular}{|c|c|c|c|c|}
\hline \multicolumn{5}{|l|}{ Sex, $n(\%)$} \\
\hline Male & Ref & Ref & Ref & Ref \\
\hline Female & $1.29[0.65,3.04]$ & $2.32[0.88,6.33]$ & $5.5[1.59,21.06]$ & $3.61[1.39,9.92]$ \\
\hline Age (years) & $1.14[1.07,1.23]$ & $1.1[1.01,1.20]$ & $1.27[1.13,1.45]$ & $1.16[1.05,1.28]$ \\
\hline \multicolumn{5}{|l|}{ APOE-ع4 allele carriers, $\mathrm{n}(\%)$} \\
\hline Non-carriers & Ref & Ref & Ref & Ref \\
\hline Heterozygous & $1.07[0.59,2.19]$ & $1.03[0.49,2.23]$ & $0.86[0.31,2.41]$ & $0.99[0.45,2.11]$ \\
\hline Homozygous & $1.33[0.50,6.34]$ & $0.57[0.17,2.01]$ & $0.72[0.10,4.03]$ & $5.03[0.86,31.43]$ \\
\hline Systolic blood pressure (mmHg) & $1.02[0.99,1.01]$ & $1.02[0.98,1.06]$ & & \\
\hline Diastolic blood pressure (mmHg) & & & $1.06[1.004,1.12]$ & $1.02[0.98,1.06]$ \\
\hline \multicolumn{5}{|l|}{ Physical activity, $n$ (\%) } \\
\hline Non-active & Ref & Ref & Ref & Ref \\
\hline Active & $0.52[0.26,1.27]$ & $0.78[0.31,1.87]$ & $0.48[0.13,1.69]$ & $0.98[0.41,2.46]$ \\
\hline Total GM $\left(\mathrm{mm}^{3}\right)$ & $1.0001[0.99,1.001]$ & $1.0001[0.99,1.001]$ & $1.0001[1.0001,1.001]$ & $1.0001[0.99,1.00001]$ \\
\hline WMH (ml) & $1.17[1.0001,1.45]$ & $1.07[0.91,1.31]$ & $1.08[0.82,1.47]$ & $1.001[0.99,1.01]$ \\
\hline $\operatorname{TIV}\left(\mathrm{mm}^{3}\right)$ & $1.0001[0.99,1.001]$ & $0.999[0.99,1.001]$ & $1.0001[0.99,1.00001]$ & $1.0001[0.99,1.00001]$ \\
\hline
\end{tabular}




\section{Association between CSF biomarkers on ePVS}

Models that were not corrected by A $\beta 40$ levels showed that higher levels of p-tau (OR [CI95\%]: 1.08 [1.02, 1.15]), t-tau (OR [CI95\%]: 1.01 [1.004, 1.01]), YKL40 (OR [CI95\%]: 1.02 [1.01, 1.02]), sTREM2 (OR [CI95\%]: 1.23 $[1.07,1.43]$ ), and neurogranin (OR [CI95\%]: 1.003 [1.001, 1.004]) were significantly associated with ePVS in the BG region. Only higher levels of CSF NfL (OR [CI95\%]: 1.04 $[1.008,1.08]$ ) and neurogranin (OR [CI95\%]: 1.003 [1.001, 1.005]) were significantly associated with BG-ePVS in $\mathrm{A} \beta+$ individuals. In the $\mathrm{CS}$ region, we showed that higher levels of p-tau (OR [CI95\%]: 1.08 [1.012, 1.16]), t-tau (OR [CI95\%]: 1.01 [1.002, 1.018]), and neurogranin (OR [CI95\%]: 1.002 [1.001, 1.004]) were significantly associated with ePVS (Supplemental Table 3, Supplemental Figure 1). Moreover, we found significant associations between higher levels of CSF A $\beta 40$ and a higher degree of PVS in both the BG and CS in the whole sample that persisted when stratifying the analyses by $A \beta$ status. After correcting for levels of CSF A $\beta 40$, significant associations between higher levels of CSF p-tau (OR [CI95\%]: 1.16 [1.03, 1.35]), t-tau (OR [CI95\%]: 1.02 [1.01, 1.04]), and neurogranin (OR [CI95\%]: 1.004 [1.001, 1.008]) (degree 2 vs degree $3+4)$ were found in the $A \beta+$ group, only in the CS region (Table 4).

\section{Discussion}

This study aimed to assess whether pathophysiological processes related to $\mathrm{AD}$, as measured by CSF biomarkers, are associated with higher degree of ePVS in a cohort of cognitively unimpaired individuals enriched for positive AD biomarkers.

We found that ePVS in the CS were associated with higher levels of CSF p-tau, t-tau, and neurogranin in $\mathrm{A} \beta+$ participants. CSF $\mathrm{p}$-tau, $\mathrm{t}$-tau and neurogranin are widely accepted biomarkers of tau protein pathophysiology, neurodegeneration, and synaptic dysfunction, respectively. These associations between AD biomarkers and ePVS survived after correcting for relevant demographic and cardiovascular risk factors, as well as CSF A $\beta 40$ levels. CSF A $\beta 40$ concentration values are typically used to normalize CSF A $\beta 42$ levels to render a superior performance (A $\beta 42 / 40$ ratio) in discriminating patients with AD [21, 22]. Since it has been described that ePVS alter CSF dynamics, it could be hypothesized that ePVS may also alter the concentrations of proteins in the CSF. We found significant associations between higher ePVS levels and higher concentrations of CSF A $\beta 40$, independent of $A \beta$ status, thus supporting this hypothesis. In addition, in models not accounting for CSF A $\beta 40$, higher ePVS levels were associated with higher levels of most of the CSF biomarkers, irrespective of the stratification by $\mathrm{A} \beta$ status. This finding suggests that levels of these CSF markers may be altered due to impaired CSF clearance and not necessarily due to the involvement of these pathophysiological mechanisms in the development of ePVS. Furthermore, we stratified the analyses in $A \beta+$ and $A \beta$ - individuals to study the associations between ePVS and CSF biomarkers within and outside the Alzheimer's continuum. Therefore, the fact that $\mathrm{p}$-tau, $\mathrm{t}$-tau, and neurogranin survived the correction for CSF A $\beta 40$ levels in $\mathrm{A} \beta+$ individuals supports the association of ePVS with core AD pathophysiological mechanisms.

We observed that the risk of ePVS was strongly associated with age. The effect of age was not specific to a given region but was equally significant in both, $\mathrm{CS}$ and BG. In turn, the effect was independent of cardiovascular risk factors. Regarding sex differences in the distribution of ePVS, we observed a significant association specific to the CS region, suggesting that women have a higher risk of ePVS in this region dependent on cardiovascular risk factors, perhaps because of specific sex-related mechanisms that also affect the formation of ePVS. Interestingly, we did not find significant results for the BG region, in line with previous work reporting differences in ePVS formation according to the brain region and sex $[7,23]$.

We additionally found a significant association between risk of ePVS and WMH and systolic blood pressure in $\mathrm{BG}$, as well as WMH and diastolic blood pressure in CS, which are in line with previous studies [24, 25]. Blood pressure effects were age-dependent and disappeared in both regions when correcting for demographic variables. Previous studies have also described strong associations between ePVS with increasing age and hypertension, but despite that, these analyses revealed that when all those variables were considered jointly, only age remained significant, as in the present study [26, 27]. In addition, we found no significant associations between WMH and ePVS after adjusting for other risk factors, which has been also reported recently [6].

Recent studies have hypothesized that additional risk factors (e.g., genetic risk factors) may contribute to a larger portion of extracellular $A \beta$ clearance, influencing the relationship between ePVS and CSF biomarkers [28]. Because $A P O E-\varepsilon 4$ enhances $A \beta$ deposition [29], several studies focused on associations between $A P O E$ genotypes and ePVS, with controversial results. In studies carried out in older individuals and/or high cardiovascular risk, significant differences were found [30, 31]. Contrary to them, some studies performed in healthy younger individuals were in line with our results and did not find significant associations between $A P O E$ and ePVS [27, 32 . Notice that even though our sample is enriched for $A P O E-\varepsilon 4$ carriers, they are relatively young and have a very low cardiovascular risk. In this context, additional 
Table. 4 Associations Perivascular Spaces in Basal Ganglia and Centrum Semiovale and CSF biomarkers (logistic and multinomial regressions). Models were adjusted by potential demographic and cardiovascular risk factors, as well as, levels of Aß40. Models were stratified by Aß42/40 positive status. Legend: $n$, sample size; SD, standard deviation; ePVS, enlarged Perivascular Spaces; BG, Basal Ganglia; CS, Centrum Semiovale; NTK, NeuroToolKit; CSF, cerebrospinal fluid.

\begin{tabular}{|c|c|c|c|c|c|c|c|c|c|}
\hline \multirow[b]{2}{*}{ Outcome } & \multicolumn{3}{|l|}{ All Individuals } & \multicolumn{3}{|c|}{$A \beta 42 / 40$ positivity $(N=122)$} & \multicolumn{3}{|c|}{$A \beta 42 / 40$ negativity $(N=200)$} \\
\hline & Biomarker & $O R$ & IC & Biomarker & $O R$ & IC & Biomarker & OR & IC \\
\hline $\begin{array}{l}B G \text { (degree } 2+3 \text { vs } \\
\text { degree 1) }\end{array}$ & $A \beta 42 / 40$ & 0.059 & {$[0.025,0.626]$} & $A \beta 42 / 40$ & & & $A \beta 42 / 40$ & & \\
\hline $\begin{array}{l}B G \text { (degree } 2+3 \text { vs } \\
\text { degree 1) }\end{array}$ & $p$-Tau $(p g / m L)$ & 0.980 & {$[0.925,1.055]$} & $p$-Tau $(p g / m L)$ & 1.022 & {$[0.937,1.161]$} & $p$-Tau $(p g / m L)$ & 0.887 & {$[0.74,1.061]$} \\
\hline $\begin{array}{c}B G \text { (degree } 2+3 \text { vs } \\
\text { degree 1) }\end{array}$ & t-Tau $(p g / m L)$ & 0.999 & {$[0.991,1.008]$} & $t$-Tau $(p g / m L)$ & 1.004 & {$[0.992,1.022]$} & $t$-Tau $(p g / m L)$ & 0.992 & {$[0.974,1.011]$} \\
\hline $\begin{array}{l}B G \text { (degree } 2+3 \text { vs } \\
\text { degree 1) }\end{array}$ & GFAP $(p g / m L)$ & 0.883 & {$[0.762,0.998]$} & GFAP $(p g / m L)$ & 0.873 & {$[0.589,1.254]$} & $\operatorname{GFAP}(p g / m L)$ & 0.895 & {$[0.758,1.021]$} \\
\hline $\begin{array}{l}B G \text { (degree } 2+3 \text { vs } \\
\text { degree 1) }\end{array}$ & $Y K L 40(\mathrm{pg} / \mathrm{mL})$ & 1.008 & {$[0.999,1.018]$} & $Y K L 40(p g / m L)$ & 1.006 & {$[0.987,1.026]$} & $Y K L 40(p g / m L)$ & 1.010 & {$[0.999,1.023]$} \\
\hline $\begin{array}{c}B G \text { (degree } 2+3 \text { vs } \\
\text { degree 1) }\end{array}$ & TREM2 $(\mathrm{pg} / \mathrm{mL})$ & 1.082 & {$[0.917,1.285]$} & TREM2 $(\mathrm{pg} / \mathrm{mL})$ & 1.127 & {$[0.814,1.583]$} & TREM2 $(\mathrm{pg} / \mathrm{mL})$ & 1.072 & {$[0.873,1.325]$} \\
\hline $\begin{array}{l}B G \text { (degree } 2+3 \text { vs } \\
\text { degree 1) }\end{array}$ & $1 L 6(p g / m L)$ & 1.108 & {$[0.943,1.324]$} & $1 L 6(p g / m L)$ & 1.192 & {$[0.854,1.708]$} & $1 L 6(p g / m L)$ & 1.119 & {$[0.918,1.413]$} \\
\hline $\begin{array}{l}B G \text { (degree } 2+3 \text { vs } \\
\text { degree 1) }\end{array}$ & $N F L(p g / m L)$ & 1.000 & {$[0.986,1.014]$} & $N F L(p g / m L)$ & 1.031 & {$[0.998,1.07]$} & $N F L(p g / m L)$ & 0.991 & {$[0.974,1.009]$} \\
\hline $\begin{array}{l}B G \text { (degree } 2+3 \text { vs } \\
\text { degree 1) }\end{array}$ & $\begin{array}{l}\text { Neurogranin (pg/ } \\
m L \text { ) }\end{array}$ & 1.001 & {$[0.999,1.004]$} & $\begin{array}{l}\text { Neurogranin (pg/ } \\
m L \text { ) }\end{array}$ & 1.002 & {$[0.999,1.007]$} & $\begin{array}{l}\text { Neurogranin (pg/ } \\
m L \text { ) }\end{array}$ & 1.001 & {$[0.998,1.005]$} \\
\hline $\begin{array}{c}B G \text { (degree } 2+3 \text { vs } \\
\text { degree 1) }\end{array}$ & $\mathrm{S100}(\mathrm{pg} / \mathrm{mL})$ & 0.850 & {$[0.177,4.13]$} & $\mathrm{S} 100(\mathrm{pg} / \mathrm{mL})$ & 1.782 & {$[0.086,42.126]$} & $\mathrm{s} 100(\mathrm{pg} / \mathrm{mL})$ & 0.810 & {$[0.115,5.683]$} \\
\hline $\begin{array}{l}B G \text { (degree } 2+3 \text { vs } \\
\text { degree 1) }\end{array}$ & $\begin{array}{l}\text { a-Synuclein (pg/ } \\
\text { mL) }\end{array}$ & 1.001 & {$[0.999,1.002]$} & $\begin{array}{l}\text { a-Synuclein (pg/ } \\
\text { mL) }\end{array}$ & 1.004 & {$[1,1.018]$} & $\begin{array}{l}\text { a-Synuclein (pg/ } \\
\text { mL) }\end{array}$ & 1.000 & {$[0.999,1.002]$} \\
\hline $\begin{array}{l}\text { CS (degree } 2 \text { vs } \\
\text { degree 1) }\end{array}$ & $A \beta 42 / 40$ & 0.001 & {$[0.00001,0.0017]$} & $A \beta 42 / 40$ & & & $A \beta 42 / 40$ & & \\
\hline $\begin{array}{c}\text { CS (degree 2 vs } \\
\text { degree 1) }\end{array}$ & $p$-Tau (pg/mL) & 0.960 & {$[0.878,1.055]$} & $p$-Tau (pg/mL) & 1.064 & {$[0.905,1.301]$} & $p$-Tau (pg/mL) & 0.824 & {$[0.669,1.003]$} \\
\hline $\begin{array}{c}\text { CS (degree 2 vs } \\
\text { degree 1) }\end{array}$ & $t$-Tau $(p g / m L)$ & 0.995 & {$[0.984,1.005]$} & $t$-Tau (pg/mL) & 1.006 & {$[0.986,1.028]$} & $t$-Tau $(p g / m L)$ & 0.984 & {$[0.964,1.004]$} \\
\hline $\begin{array}{l}\text { CS (degree } 2 \text { vs } \\
\text { degree 1) }\end{array}$ & GFAP $(p g / m L)$ & 0.935 & {$[0.806,1.085]$} & GFAP (pg/mL) & 1.025 & {$[0.673,1.558]$} & GFAP $(p g / m L)$ & 0.921 & {$[0.78,1.095]$} \\
\hline $\begin{array}{c}\text { CS (degree } 2 \text { vs } \\
\text { degree 1) }\end{array}$ & $Y K L 40(\mathrm{pg} / \mathrm{mL})$ & 0.997 & {$[0.988,1.006]$} & $Y K L 40(\mathrm{pg} / \mathrm{mL})$ & 1.010 & {$[0.99,1.033]$} & $Y K L 40(p g / m L)$ & 0.992 & {$[0.981,1.003]$} \\
\hline $\begin{array}{c}\text { CS (degree } 2 \text { vs } \\
\text { degree 1) }\end{array}$ & TREM2 $(\mathrm{pg} / \mathrm{mL})$ & 0.899 & {$[0.755,1.067]$} & TREM2 $(\mathrm{pg} / \mathrm{mL})$ & 0.883 & {$[0.636,1.208]$} & $\operatorname{TREM} 2(\mathrm{pg} / \mathrm{mL})$ & 0.911 & {$[0.724,1.143]$} \\
\hline $\begin{array}{c}\text { CS (degree 2 vs } \\
\text { degree 1) }\end{array}$ & $1 L 6(p g / m L)$ & 1.016 & {$[0.866,1.21]$} & $1 L 6(p g / m L)$ & 1.098 & {$[0.722,1.759]$} & $1 L 6(p g / m L)$ & 0.991 & {$[0.825,1.212]$} \\
\hline $\begin{array}{c}\text { CS (degree } 2 \text { vs } \\
\text { degree 1) }\end{array}$ & $N F L(p g / m L)$ & 0.992 & {$[0.979,1.002]$} & $N F L(p g / m L)$ & 0.992 & {$[0.962,1.024]$} & $N F L(p g / m L)$ & 0.992 & {$[0.974,1.002]$} \\
\hline $\begin{array}{l}\text { CS (degree 2 vs } \\
\text { degree 1) }\end{array}$ & $\begin{array}{l}\text { Neurogranin (pg/ } \\
m L)\end{array}$ & 1.001 & {$[0.998,1.003]$} & $\begin{array}{l}\text { Neurogranin (pg/ } \\
\mathrm{mL} \text { ) }\end{array}$ & 1.003 & {$[0.998,1.009]$} & $\begin{array}{l}\text { Neurogranin (pg/ } \\
m L \text { ) }\end{array}$ & 1.000 & {$[0.997,1.004]$} \\
\hline $\begin{array}{c}\text { CS (degree } 2 \text { vs } \\
\text { degree 1) }\end{array}$ & $\mathrm{S100}(\mathrm{pg} / \mathrm{mL})$ & 0.960 & {$[0.189,5.014]$} & $\mathrm{S100}(\mathrm{pg} / \mathrm{mL})$ & 0.445 & {$[0.018,11.609]$} & $S 100(\mathrm{pg} / \mathrm{mL})$ & 1.155 & {$[0.146,9.506]$} \\
\hline $\begin{array}{l}\text { CS (degree } 2 \text { vs } \\
\text { degree 1) }\end{array}$ & $\begin{array}{l}\text { a-Synuclein (pg/ } \\
\text { mL) }\end{array}$ & 1.003 & {$[1,1.007]$} & $\begin{array}{l}\text { a-Synuclein (pg/ } \\
\text { mL) }\end{array}$ & 1.013 & {$[0.998,1.038]$} & $\begin{array}{l}\text { a-Synuclein (pg/ } \\
\text { mL) }\end{array}$ & 1.003 & {$[1,1.007]$} \\
\hline $\begin{array}{l}\text { CS (degree } 3+4 \text { vs } \\
\text { degree 1) }\end{array}$ & $A \beta 42 / 40$ & $\sim 0$ & {$[0,0.8373]$} & $A \beta 42 / 40$ & & & $A \beta 42 / 40$ & & \\
\hline $\begin{array}{l}\text { CS (degree } 3+4 \text { vs } \\
\text { degree 1) }\end{array}$ & $p$-Tau (pg/mL) & 1.010 & {$[0.946,1.112]$} & $p$-Tau $(p g / m L)$ & 1.152 & {$[0.986,1.487]$} & $p$-Tau (pg/mL) & 0.814 & {$[0.643,1.011]$} \\
\hline $\begin{array}{l}\text { CS (degree } 3+4 \text { vs } \\
\text { degree 1) }\end{array}$ & $t$-Tau $(p g / m L)$ & 1.000 & {$[0.992,1.011]$} & $t$-Tau (pg/mL) & 1.013 & {$[0.996,1.039]$} & $t$-Tau (pg/mL) & 0.982 & {$[0.959,1.003]$} \\
\hline $\begin{array}{l}\text { CS (degree } 3+4 \text { vs } \\
\text { degree 1) }\end{array}$ & $\operatorname{GFAP}(p g / m L)$ & 1.021 & {$[0.876,1.217]$} & $\operatorname{GFAP}(p g / m L)$ & 1.280 & {$[0.77,2.285]$} & GFAP $(p g / m L)$ & 1.009 & {$[0.853,1.226]$} \\
\hline
\end{tabular}


Table. 4 (continued)

\begin{tabular}{|c|c|c|c|c|c|c|c|c|c|}
\hline \multirow[b]{2}{*}{ Outcome } & \multicolumn{3}{|l|}{ All Individuals } & \multicolumn{3}{|c|}{$A \beta 42 / 40$ positivity $(N=122)$} & \multicolumn{3}{|c|}{$A \beta 42 / 40$ negativity $(N=200)$} \\
\hline & Biomarker & $O R$ & IC & Biomarker & OR & IC & Biomarker & OR & IC \\
\hline $\begin{array}{l}\text { CS (degree } 3+4 \text { vs } \\
\text { degree 1) }\end{array}$ & $Y K L 40(p g / m L)$ & 1.002 & {$[0.993,1.012]$} & $Y K L 40(p g / m L)$ & 1.010 & {$[0.989,1.036]$} & $Y K L 40(p g / m L)$ & 0.999 & {$[0.988,1.01]$} \\
\hline $\begin{array}{l}\text { CS (degree } 3+4 \text { vs } \\
\text { degree 1) }\end{array}$ & $\operatorname{TREM} 2(\mathrm{pg} / \mathrm{mL})$ & 1.017 & {$[0.808,1.279]$} & $\operatorname{TREM} 2(\mathrm{pg} / \mathrm{mL})$ & 1.008 & {$[0.643,1.604]$} & $\operatorname{TREM} 2(\mathrm{pg} / \mathrm{mL})$ & 1.051 & {$[0.78,1.421]$} \\
\hline $\begin{array}{l}\text { CS (degree } 3+4 \text { vs } \\
\text { degree 1) }\end{array}$ & $1 L 6(p g / m L)$ & 1.118 & {$[0.885,1.429]$} & $1 L 6(p g / m L)$ & 1.485 & {$[0.898,3.101]$} & $1 \mathrm{~L} 6(\mathrm{pg} / \mathrm{mL})$ & 1.079 & {$[0.763,1.484]$} \\
\hline $\begin{array}{l}\text { CS (degree } 3+4 \text { vs } \\
\text { degree 1) }\end{array}$ & $N F L(p g / m L)$ & 0.994 & {$[0.982,1.004]$} & $N F L(p g / m L)$ & 1.002 & {$[0.972,1.039]$} & $N F L(p g / m L)$ & 0.994 & {$[0.977,1.004]$} \\
\hline $\begin{array}{l}\text { CS (degree } 3+4 \text { vs } \\
\text { degree 1) }\end{array}$ & $\begin{array}{l}\text { Neurogranin (pg/ } \\
m L)\end{array}$ & 1.001 & {$[0.999,1.004]$} & $\begin{array}{l}\text { Neurogranin (pg/ } \\
\mathrm{mL} \text { ) }\end{array}$ & 1.003 & {$[0.999,1.009]$} & $\begin{array}{l}\text { Neurogranin (pg/ } \\
m L)\end{array}$ & 1.000 & {$[0.996,1.005]$} \\
\hline $\begin{array}{l}\text { CS (degree } 3+4 \text { vs } \\
\text { degree 1) }\end{array}$ & $S 100(p g / m L)$ & 0.403 & {$[0.047,3.219]$} & $\mathrm{S100}(\mathrm{pg} / \mathrm{mL})$ & 1.286 & {$[0.017,113.076]$} & $S 100(p g / m L)$ & 0.322 & {$[0.02,4.771]$} \\
\hline $\begin{array}{l}\text { CS (degree } 3+4 \text { vs } \\
\text { degree 1) }\end{array}$ & $\begin{array}{l}\text { a-Synuclein (pg/ } \\
\text { mL) }\end{array}$ & 1.004 & {$[1,1.011]$} & $\begin{array}{l}\text { a-Synuclein (pg/ } \\
\text { mL) }\end{array}$ & 1.016 & {$[0.999,1.051]$} & $\begin{array}{l}\text { a-Synuclein (pg/ } \\
\text { mL) }\end{array}$ & 1.003 & {$[0.997,1.01]$} \\
\hline $\begin{array}{l}\text { CS (degree } 3+4 \text { vs } \\
\text { degree } 2)\end{array}$ & $A \beta 42 / 40$ & 0.000 & {$[0,0.01349]$} & $A \beta 42 / 40$ & & & $A \beta 42 / 40$ & & \\
\hline $\begin{array}{l}\text { CS (degree } 3+4 \text { vs } \\
\text { degree 2) }\end{array}$ & $p$-Tau (pg/mL) & 1.037 & {$[0.981,1.108]$} & $p$-Tau (pg/mL) & 1.158 & {$[1.032,1.351]$} & $p$-Tau (pg/mL) & 0.954 & {$[0.797,1.135]$} \\
\hline $\begin{array}{l}\text { CS (degree } 3+4 \text { vs } \\
\text { degree 2) }\end{array}$ & $t$-Tau $(p g / m L)$ & 1.004 & {$[0.997,1.012]$} & $t$-Tau $(p g / m L)$ & 1.020 & {$[1.005,1.041]$} & $t$-Tau $(p g / m L)$ & 0.996 & {$[0.977,1.015]$} \\
\hline $\begin{array}{l}\text { CS (degree } 3+4 \text { vs } \\
\text { degree 2) }\end{array}$ & GFAP $(p g / m L)$ & 1.083 & {$[0.963,1.234]$} & GFAP $(p g / m L)$ & 1.355 & {$[0.961,2.05]$} & GFAP $(p g / m L)$ & 1.065 & {$[0.934,1.229]$} \\
\hline $\begin{array}{l}\text { CS (degree } 3+4 \text { vs } \\
\text { degree } 2)\end{array}$ & $Y K L 40(p g / m L)$ & 1.005 & {$[0.997,1.013]$} & YKL4O (pg/mL) & 1.006 & {$[0.991,1.022]$} & YKL4O (pg/mL) & 1.006 & {$[0.996,1.016]$} \\
\hline $\begin{array}{l}\text { CS (degree } 3+4 \text { vs } \\
\text { degree } 2)\end{array}$ & $\operatorname{TREM} 2(\mathrm{pg} / \mathrm{mL})$ & 1.112 & {$[0.939,1.322]$} & TREM2 $(\mathrm{pg} / \mathrm{mL})$ & 1.231 & {$[0.906,1.719]$} & TREM2 $(\mathrm{pg} / \mathrm{mL})$ & 1.036 & {$[0.831,1.294]$} \\
\hline $\begin{array}{l}\text { CS (degree } 3+4 \text { vs } \\
\text { degree } 2)\end{array}$ & $1 L 6(p g / m L)$ & 1.072 & {$[0.904,1.268]$} & $1 / 6(p g / m L)$ & 1.371 & {$[0.954,2.11]$} & IL6 (pg/mL) & 0.993 & {$[0.783,1.217]$} \\
\hline $\begin{array}{l}\text { CS (degree } 3+4 \text { vs } \\
\text { degree 2) }\end{array}$ & $N F L(p g / m L)$ & 1.009 & {$[0.996,1.023]$} & $N F L(p g / m L)$ & 1.008 & {$[0.985,1.032]$} & $N F L(p g / m L)$ & 1.012 & {$[0.993,1.031]$} \\
\hline $\begin{array}{l}\text { CS (degree } 3+4 \text { vs } \\
\text { degree 2) }\end{array}$ & $\begin{array}{l}\text { Neurogranin (pg/ } \\
m L)\end{array}$ & 1.002 & {$[1,1.003]$} & $\begin{array}{l}\text { Neurogranin (pg/ } \\
m L \text { ) }\end{array}$ & 1.004 & {$[1.001,1.008]$} & $\begin{array}{l}\text { Neurogranin (pg/ } \\
\mathrm{mL} \text { ) }\end{array}$ & 1.002 & {$[0.999,1.005]$} \\
\hline $\begin{array}{l}\text { CS (degree } 3+4 \text { vs } \\
\text { degree 2) }\end{array}$ & $S 100(\mathrm{pg} / \mathrm{mL})$ & 0.505 & {$[0.094,2.614]$} & $\mathrm{S100}(\mathrm{pg} / \mathrm{mL})$ & 0.548 & {$[0.028,8.746]$} & $\mathrm{S100}(\mathrm{pg} / \mathrm{mL})$ & 0.476 & {$[0.051,4.062]$} \\
\hline $\begin{array}{l}\text { CS (degree } 3+4 \text { vs } \\
\text { degree } 2)\end{array}$ & $\begin{array}{l}\text { a-Synuclein (pg/ } \\
\text { mL) }\end{array}$ & 1.000 & {$[0.999,1.001]$} & $\begin{array}{l}\text { a-Synuclein (pg/ } \\
\text { mL) }\end{array}$ & 1.001 & {$[1,1.004]$} & $\begin{array}{l}\text { a-Synuclein (pg/ } \\
\text { mL) }\end{array}$ & 0.999 & {$[0.996,1.001]$} \\
\hline
\end{tabular}

studies become essential and relevant for the near future in this field of research.

Several limitations must be considered for this study. Particularly challenging was the evaluation of MRIs with very small ePVS that can be seen as faint, indistinct high signal structures since those can cause a change from one category to another if considered. This difficulty has been previously described [8] and addressed by maintaining a general impression of the region and trying to match it with the categories provided. Moreover, although several PVS rating methods have been developed, we restricted our study to a single rating scale using only a single MRI protocol and limiting the quantification of PVS to two brain regions. Also, dichotomization of PVS scales could cause a substantial reduction in statistical power, thus increasing the change of false negatives in our results. Another limitation stems from the fact that CSF biomarkers showed a high correlation among them in our sample. In particular, p-tau, t-tau, and neurogranin had pair-wise Pearson's $r>0.90$. This high correlation might reflect a tight association between tau pathophysiology, AD-related neurodegeneration, and synaptic dysfunction in our sample or be due to other technical or physiological confounding factors. Nevertheless, p-tau measurements obtained with the same essay have been shown to be able to predict clinical decline and conversion to $\mathrm{AD}$ [33] and have been approved for clinical use [34]. Finally, even though the associations between ePVS and p-tau, $\mathrm{t}$-tau, and neurogranin in $A \beta+$ individuals survived the correction for $A \beta 40$ levels, $A \beta 40$ cannot be interpreted 
as a valid marker of overall cerebral protein clearance in physiological conditions. However, the fact that the biomarkers that survive correction for $A \beta 40$ are also significant without it strongly argues for our main result to be robust against this correction.

A strength of our study is the use of high-resolution T2 MRI scans and a small voxel size $\left(1 \mathrm{~mm}^{3}\right.$, isotropic), recommended for PVS rating [8]. An additional substantial strength is our sample-based design, which is a large cohort of cognitively unimpaired individuals after an exhaustive neuropsychological and clinical screening procedure. In addition, results are not likely to be severely confounded by comorbidities of dementia, being the individuals of the study at a low mean cardiovascular risk. The studied cohort has a high prevalence of $A P O E-\varepsilon 4$ carriers, thus bringing a higher statistical power in comparison with studies with a similar number of individuals that are genetically closer to the general population [35]. Our sample also has a high prevalence of positive CSF $A \beta$, individuals compared with other studies.

In conclusion, our findings showed, for the first time, an association between ePVS in the CS and higher levels of CSF core AD biomarkers $\mathrm{p}$-tau and $\mathrm{t}$-tau, as well as CSF neurogranin, in cognitively unimpaired $A \beta+$ individuals. This result supports the association between ePVS and specific AD pathophysiological mechanisms occurring in the early stages of the Alzheimer's continuum.

\begin{abstract}
Abbreviations
ALFA: ALzheimer and FAmilies; $A \beta$ : $\beta$-Amyloid; $A \beta 40$ : Amyloid- $\beta$ 40; $A \beta 42$ : Amyloid- $\beta$ 42; AD: Alzheimer disease; APOE: Apolipoprotein E; BG: Basal ganglia; CS: Centrum semiovale; CSF: Cerebrospinal fluid; ePVS: Enlarged perivascular spaces; GM: Gray matter; GFAP: Glial fibrillary acidic protein; IL-6: Interleukin-6; ISF: Brain interstitial fluid; NfL: Neurofilament light; MRI: Magnetic resonance imaging; PVS: Perivascular spaces; p-tau: Phosphorylated tau; STREM: Soluble triggering receptor expressed on myeloid cells 2 (TREM2); t-tau: Total tau; TIV: Total intracranial volume; WMH: White matter hyperintensities.
\end{abstract}

\section{Supplementary Information}

The online version contains supplementary material available at https://doi. org/10.1186/s13195-021-00878-5.

Additional file 1: Figure S1. Association models between Alzheimer's Disease CSF biomarkers and enlargement of Perivascular Spaces.

Additional file 2: Table S1. Characteristics of the sample stratified by A $342 / 40$ status across degrees of Perivascular Spaces. Legend: N, sample size; $n$, count of individuals for each categorical variable; SD, standard deviation; ePVS, enlarged Perivascular Spaces; BG, Basal Ganglia; CS, Centrum Semiovale; CAIDE, Cardiovascular Risk Factors, Aging and Incidence of Dementia; BMI, Body Mass Index; WMH, White Matter Hyperintensities; GM, Gray Matter volume; TIV, Total Intracranial volume. Table S2. Individual associations between enlargement of Perivascular Spaces in Basal Ganglia and Centrum Semiovale regions, and demographic and cardiovascular risk factors. Legend: $n$, count of individuals for each categorical variable; SD, standard deviation; ePVS, enlarged Perivascular Spaces; BG, Basal
Ganglia; CS, Centrum Semiovale; CAIDE, Cardiovascular Risk Factors, Aging and Incidence of Dementia; WMH, White Matter Hyperintensities; GM, Gray Matter volume; TIV, Total Intracranial volume. Table S3. Associations between Perivascular Spaces in Basal Ganglia and Centrum Semiovale and CSF biomarkers (logistic and multinomial regressions). Models were adjusted by potential demographic and cardiovascular risk factors. Models were stratified by $A \beta 42 / 40$ positive status. Legend: $n$, sample size; SD, standard deviation; ePVS, enlarged Perivascular Spaces; BG, Basal Ganglia; CS, Centrum Semiovale; NTK, NeuroToolKit; CSF, cerebrospinal fluid.

\section{Acknowledgements}

This publication is part of the ALFA (ALzheimer and FAmilies) study. The authors would like to express their most sincere gratitude to the ALFA project participants, without whom this research would have not been possible. We thank Roche Diagnostics International Ltd. for providing the kits to measure CSF biomarkers of ALFA+ study participants.

Collaborators of the ALFA study are Annabella Beteta, Anna Brugulat, Raffaele Cacciaglia, Alba Cañas, Carme Deulofeu, Irene Cumplido, Ruth Dominguez, Maria Emilio, Karine Fauria, Sherezade Fuentes, Laura Hernandez, Gema Huesa, Jordi Huguet, Paula Marne, Tania Menchón, Albina Polo, Sandra Pradas, Blanca Rodriguez-Fernandez, Aleix Sala-Vila, Gonzalo Sánchez-Benavides, Gemma Salvadó, Anna Soteras, and Marc Vilanova.

The measuring range of the assay is 200 (lower technical limit)-1700 pg/ $\mathrm{mL}$ (upper technical limit). The performance of the assay beyond the upper technical limit has not been formally established. Therefore, the use of values above the upper technical limit, which are provided based on an extrapolation of the calibration curve, is restricted to exploratory research purposes and is excluded for clinical decision making or for the derivation of medical decision points.

COBAS, COBAS E, and ELECSYS are trademarks of Roche.

\section{Authors' contributions}

Natalia Vilor-Tejedor, PhD:Conceived the presented idea. Developed the theoretical formalism and designed the models. Contributed to sample preparation. Analyzed the data. Interpreted the data. Took the lead in writing the manuscript. lacopo Ciampa, MD, MSc:Contributed to sample preparation; analyzed the data; interpreted the data. Provided critical feedback and helped shape the research, analysis, and manuscript. Grégory Operto, PhD:Major role in the acquisition and preparation of neuroimaging data. Provided critical feedback and helped shape the research, analysis, and manuscript. Carles Falcón, PhD:Major role in the acquisition and preparation of neuroimaging data. Provided critical feedback and helped shape the research, analysis, and manuscript. Marc Suárez-Calvet, MD, PhD:Major role in the acquisition and preparation of CSF data. Developed the theoretical formalism and designed the models. Provided critical feedback and helped shape the research, analysis, and manuscript. Marta Crous-Bou, PhD:Provided critical feedback and helped shape the research, analysis and manuscript. Mahnaz Shekari, MD:Contributed to sample preparation. Provided critical feedback and helped shape the research, analysis, and manuscript. Eider M Arenaza-Urquijo, PhD:Developed the theoretical formalism and designed the models. Provided critical feedback and helped shape the research, analysis, and manuscript. Marta Milà-Alomà, MD:Contributed to CSF sample preparation. Provided critical feedback and helped shape the research, analysis, and manuscript. Oriol Grau-Rivera, MD, PhD:Provided critical feedback and helped shape the research, analysis, and manuscript. Carolina Minguillón, PhD:Contributed to sample coordination. Provided critical feedback and helped shape the research, analysis, and manuscript. Gwendlyn Kollmorgen, PhD:Major role in the acquisition and preparation of the data. Provided NeuroToolKit assay and organized CSF measurements. Provided critical feedback and helped shape the research, analysis, and manuscript. Henrik Zetterberg, PhD:Major role in the acquisition and preparation of the data. Supervised the CSF biomarker measurements quantification. Kaj Blennow, PhD:Major role in the acquisition and preparation of the data. Supervised the CSF biomarker measurements quantification. Provided critical feedback and helped shape the research, analysis, and manuscript. Roderic Guigo, PhD:Provided critical feedback and helped shape the research, analysis, and manuscript. José Luis Molinuevo, MD, PhD:Developed the theoretical formalism and designed the models. Supervised the project. Provided critical feedback and helped shape the research, analysis, and manuscript. Juan Domingo Gispert, PhD:Conceived the presented idea. Developed 
the theoretical formalism and designed the models. Supervised the project. Provided critical feedback and helped shape the research, analysis, and manuscript. The author(s) read and approved the final manuscript.

\section{Funding}

The project leading to these results has received funding from "la Caixa" Foundation (ID 100010434), under agreement LCF/PR/GN17/50300004 and the Alzheimer's Association and an international anonymous charity foundation through the TriBEKa Imaging Platform project (TriBEKa-17-519007). Additional support has been received from the Health Department of the Catalan Government (Health Research and Innovation Strategic Plan (PERIS) 2016-2020 grant\# SLT002/16/00201) and the Universities and Research Secretariat, Ministry of Business and Knowledge of the Catalan Government under the grant no. 2017-SGR-892. All CRG authors acknowledge the support of the Spanish Ministry of Science, Innovation and Universities to the EMBL partnership, the Centro de Excelencia Severo Ochoa, and the CERCA Programme/Generalitat de Catalunya. NV-T is funded by a post-doctoral grant, Juan de la Cierva Programme (FJC2018-038085-I), Ministry of Science and Innovation- Spanish State Research Agency. MS-C received funding from the European Union's Horizon 2020 Research and Innovation Program under the Marie SklodowskaCurie action grant agreement No 752310, and currently receives funding from Instituto de Salud Carlos III (PI19/00155) and from the Spanish Ministry of Science, Innovation and Universities (Juan de la Cierva Programme grant IJC2018-037478-I). EMAU is supported by the Spanish Ministry of Science, Innovation and Universities-Spanish State Research Agency (RYC2018026053-I). OGR is supported by the Spanish Ministry of Science, Innovation and Universities (FJCl-2017-33437). JDG is supported by the Spanish Ministry of Science and Innovation (RYC-2013-13054). KB is supported by the Swedish Research Council (\#2017-00915), the Alzheimer Drug Discovery Foundation (ADDF), USA (\#RDAPB-201809-2016615), the Swedish Alzheimer Foundation (\#AF-742881), Hiärnfonden, Sweden (\#FO2017-0243), the Swedish state under the agreement between the Swedish government and the County Councils, the ALF-agreement (\#ALFGBG-715986), and European Union Joint Program for Neurodegenerative Disorders (JPND2019-466-236). HZ is a Wallenberg Scholar supported by grants from the Swedish Research Council (\#201802532), the European Research Council (\#681712), the Swedish state under the agreement between the Swedish government and the County Councils, the ALF-agreement (\#ALFGBG-720931), the ADDF, USA (\#201809-2016862), and the UK Dementia Research Institute at UCL.

\section{Availability of data and materials}

Due to participant's privacy, individual level data cannot be made publicly available. Researchers who wish to use data of the ALFA study must obtain approval from the ALFA study Management Team.

\section{Declarations}

\section{Ethics approval and consent to participate}

The study was conducted following the directives of Spanish Law 14/2007, of 3rd July, on Biomedical Research (Ley 14/2007 de Investigación Biomédica). Study protocols were approved by the Clinical Research Ethics Committee "Parc de Salut Mar", Barcelona. All participants accepted the study procedures by signing the study's informed consent form.

\section{Consent for publication}

Not applicable.

\section{Competing interests}

GK is a full-time employee of Roche Diagnostics $\mathrm{GmbH}$. The remaining authors declare that they have no conflict of interest. HZ has served at scientific advisory boards for Denali, Roche Diagnostics, Wave, Samumed, and CogRx; has given lectures in symposia sponsored by Fujirebio, Alzecure, and Biogen;and is a co-founder of Brain Biomarker Solutions in Gothenburg AB (BBS), which is a part of the GU Ventures Incubator Program. JLM has served/serves as a consultant or at advisory boards for the following for-profit companies or has given lectures in symposia sponsored by the following for-profit companies: Roche Diagnostics, Genentech, Novartis, Lundbeck, Oryzon, Biogen, Lilly, Janssen, Green Valley, MSD, Eisai, Alector, BioCross, GE Healthcare, ProMIS Neurosciences. KB has served as a consultant, at advisory boards, or at data monitoring committees for Abcam, Axon, Biogen, JOMDD/Shimadzu. Julius
Clinical, Lilly, MagQu, Novartis, Roche Diagnostics, and Siemens Healthineers, and is a co-founder of Brain Biomarker Solutions in Gothenburg AB (BBS), which is a part of the GU Ventures Incubator Program. The other co-authors declare that they have no competing interests.

\section{Author details}

${ }^{1}$ Barcelonaßeta Brain Research Center (BBRC), Pasqual Maragall Foundation, Barcelona, Spain. ${ }^{2}$ Centre for Genomic Regulation (CRG), The Barcelona Institute for Science and Technology, Barcelona, Spain. ${ }^{3}$ Department of Clinical Genetics, Erasmus Medical Center, Rotterdam, The Netherlands. ${ }^{4}$ Universitat Pompeu Fabra, Barcelona, Spain. ${ }^{5}$ Department of Radiology, Hospital Universitari Sagrat Cor, Barcelona, Spain. ${ }^{6}$ IMIM (Hospital del Mar Medical Research Institute), Barcelona, Spain. ${ }^{7}$ Centro de Investigación Biomédica en Red de Fragilidad Y Envejecimiento Saludable (CIBERFES), Madrid, Spain. ${ }^{8}$ Centro de Investigación Biomédica en Red Bioingeniería, Biomateriales Y Nanomedicina, Madrid, Spain. ${ }^{9}$ Servei de Neurologia, Hospital del Mar, Barcelona, Spain. ${ }^{10}$ Department of Epidemiology, Harvard T.H. Chan School of Public Health, Boston, MA, USA. ${ }^{11}$ Cancer Epidemiology Research Program, Catalan Institute of Oncology (ICO), Hospitalet del Llobregat, Spain. ${ }^{12}$ Roche Diagnostics GmbH, Penzberg, Germany. ${ }^{13}$ Department of Psychiatry and Neurochemistry, Institute of Neuroscience and Physiology, University of Gothenburg, Mölndal, Sweden. ${ }^{14}$ Clinical Neurochemistry Laboratory, Sahlgrenska University Hospital, Mölndal, Sweden. ${ }^{15}$ Department of Neurodegenerative Disease, UCL Institute of Neurology, Queen Square, London, UK. ${ }^{16}$ Dementia Research Institute At UCL, London, UK.

\section{Received: 30 September 2020 Accepted: 21 July 2021}

Published online: 05 August 2021

\section{References}

1. Rudie JD, Rauschecker AM, Nabavizadeh SA, Mohan S. Neuroimaging of dilated perivascular spaces: from benign and pathologic causes to mimics. J Neuroimaging. 2018;28:139-49.

2. Kwee RM, Kwee TC. Virchow-Robin spaces at MR imaging. Radiographics. 2007. https://doi.org/10.1148/rg.274065722.

3. Cherian I, et al. Exploring the Virchow-Robin spaces function: a unified theory of brain diseases. Surg Neurol Int. 2016;7:711.

4. Ding J, et al. Large perivascular spaces visible on magnetic resonance imaging, cerebral small vessel disease progression, and risk of dementia. JAMA Neurol. 2017;74:1105.

5. Debette S, Schilling S, Duperron MG, Larsson SC, Markus HS. Clinical significance of magnetic resonance imaging markers of vascular brain injury: a systematic review and meta-analysis. JAMA Neurol. 2019;76:81-94.

6. Francis F, Ballerini L, Wardlaw JM. Perivascular spaces and their associations with risk factors, clinical disorders and neuroimaging features: a systematic review and meta-analysis. Int J Stroke. 2019;14:359-71.

7. Wardlaw JM, et al. Perivascular spaces in the brain: anatomy, physiology and pathology. Nat Rev Neurol. 2020;16:137-53.

8. Wardlaw JM, et al. Neuroimaging standards for research into small vessel disease and its contribution to ageing and neurodegeneration. The Lancet Neurology. 2013. https://doi.org/10.1016/S1474-4422(13)70124-8.

9. Weller RO, Hawkes CA, Kalaria RN, Werring DJ, Carare RO. White matter changes in dementia: role of impaired drainage of interstitial fluid. Brain Pathol. 2015;25:63-78.

10. Wuerfel J, et al. Perivascular spaces-MRI marker of inflammatory activity in the brain? Brain. 2008;131:2332-40.

11. Satizabal CL, Zhu Y-C, Dufouil C, Tzourio C. Inflammatory proteins and the severity of dilated Virchow-Robin spaces in the elderly. J Alzheimer's Dis. 2012;33:323-8.

12. Milà-Alomà, M. et al. Amyloid- $\beta$, tau, synaptic, neurodegeneration and glial biomarkers in the preclinical stage of the Alzheimer's continuum. Alzheimer's \% Dement. (2020) doi:https://doi.org/10.1002/ALZ.12131.

13. Jack CR, et al. NIA-AA Research Framework: Toward a biological definition of Alzheimer's disease. Alzheimer's and Dementia. 2018;14:535-62.

14. Molinuevo IL, et al. The ALFA project: A research platform to identify early pathophysiological features of Alzheimer's disease. Alzheimer's Dement Transl Res Clin Interv. 2016;2:82-92. 
15. Schmidt, P. Bayesian inference for structured additive regression models for large-scale problems with applications to medical imaging. (2017)

16. Potter GM, Chappell FM, Morris Z, Wardlaw JM. Cerebral perivascular spaces visible on magnetic resonance imaging: Development of a qualitative rating scale and its observer reliability. Cerebrovasc Dis. 2015;39:224-31.

17. Milà-Alomà, Marta; Salvadó, Gemma; Shekari, M. et al. Comparative Analysis of Different Definitions of Amyloid- $\beta$ Positivity to Detect Early Downstream Pathophysiological Alterations in Preclinical Alzheimer. J. Prev. Alzheimer's Dis. in press, (2020).

18. Comellas AR, et al. Validation of a spanish short version of the minnesota leisure time physical activity questionnaire (vrem). Rev Esp Salud Publica. 2012;86:495-508.

19. Kivipelto $M$, et al. Risk score for the prediction of dementia risk in 20 years among middle aged people: a longitudinal, population-based study. Lancet Neurol. 2006;5:735-41.

20. Radmanesh F, et al. Accuracy of imputation to infer unobserved APOE epsilon alleles in genome-wide genotyping data. Eur J Hum Genet. 2014;22:1239-42.

21. Hansson O, Lehmann $S$, Otto $M$, Zetterberg H, Lewczuk P. Advantages and disadvantages of the use of the CSF Amyloid $\beta$ (A $\beta$ ) $42 / 40$ ratio in the diagnosis of Alzheimer's Disease. Alzheimer's Research and Therapy. 2019;11:1-15

22. Olson JM, Tongprasearth K, Nitz DA. Subiculum neurons map the current axis of travel. Nat Neurosci. 2017;20:170-2

23. Zhang, C. et al. Risk Factors of Dilated Virchow-Robin Spaces Are Different in Various Brain Regions. PLoS One 9, e105505 (2014).

24. Ballerini, L. et al. Computational quantification of brain perivascular space morphologies: associations with vascular risk factors and white matter hyperintensities. a study in the Lothian Birth Cohort 1936. Neurolmage Clin. 25, 102120 (2020).

25. Loos, C. M. J., Klarenbeek, P., Van Oostenbrugge, R. J. \& Staals, J. Association between perivascular spaces and progression of white matter hyperintensities in lacunar stroke patients. PLoS One 10, (2015).
26. Heier, L. A. et al. Large Virchow-Robin Spaces: MR-Clinical Correlation.

27. Zhu YC, et al. Severity of dilated Virchow-Robin spaces is associated with age, blood pressure, and MRI markers of small vessel disease: a population-based study. Stroke. 2010. https://doi.org/10.1161/STROK EAHA.110.591586.

28. Boespflug EL, et al. Targeted assessment of enlargement of the perivascular space in Alzheimer's disease and vascular dementia subtypes implicates astroglial involvement specific to Alzheimer's disease. J Alzheimer's Dis. 2018;66:1587-97.

29. Liu CC, et al. ApoE4 Accelerates early seeding of amyloid pathology. Neuron. 2017;96:1024-1032.e3.

30. Laveskog, A. et al. Associations of vascular risk factors and APOE genotype with perivascular spaces among community-dwelling older adults. J. Am. Heart Assoc. 9, e015229 (2020).

31. Luo X, et al. Associations between APOE genotype and cerebral smallvessel disease: A longitudinal study. Oncotarget. 2017. https://doi.org/10. 18632/oncotarget.17724.

32. Adams HHH, et al. Determinants of Enlarged Virchow-Robin Spaces: The UNIVRSE Consortium. Alzheimer's Dement. 2014;10:P408.

33. Blennow K, et al. Predicting clinical decline and conversion to Alzheimer's disease or dementia using novel Elecsys A $\beta(1-42)$, pTau and tTau CSF immunoassays. Sci Rep. 2019;9:1-11.

34. Lifke V, et al. Elecsys ${ }^{\circledR}$ Total-Tau and Phospho-Tau (181P) CSF assays: Analytical performance of the novel, fully automated immunoassays for quantification of tau proteins in human cerebrospinal fluid. Clin Biochem. 2019;72:30-8.

35. Cacciaglia R, et al. Effects of APOE - $\varepsilon 4$ allele load on brain morphology in a cohort of middle-aged healthy individuals with enriched genetic risk for Alzheimer's disease. Alzheimer's Dement. 2018;14:902-12.

\section{Publisher's Note}

Springer Nature remains neutral with regard to jurisdictional claims in published maps and institutional affiliations.
Ready to submit your research? Choose BMC and benefit from:

- fast, convenient online submission

- thorough peer review by experienced researchers in your field

- rapid publication on acceptance

- support for research data, including large and complex data types

- gold Open Access which fosters wider collaboration and increased citations

- maximum visibility for your research: over $100 \mathrm{M}$ website views per year

At $\mathrm{BMC}$, research is always in progress.

Learn more biomedcentral.com/submissions 